\title{
Modeling and Synthesis of Ag and Ag/Ni Allied Bimetallic Nanoparticles by Green Method: Optical and Biological Properties
}

\author{
Anuoluwa Abimbola Akinsiku (D, ${ }^{1}$ Enock Olugbenga Dare ${ }^{D},{ }^{2}$ Kolawole Oluseyi Ajanaku, \\ Olayinka Oyewale Ajani, ${ }^{1}$ Joseph Adebisi O. Olugbuyiro, ${ }^{1}$ \\ Tolutope Oluwasegun Siyanbola, ${ }^{1}$ Oluwaseun Ejilude, ${ }^{3}$ and Moses Eterigho Emetere ${ }^{4,5}$ \\ ${ }^{1}$ Department of Chemistry, Covenant University, PMB 1023, Ota, Ogun State, Nigeria \\ ${ }^{2}$ Department of Chemistry, Federal University of Agriculture, PMB 2240, Alabata Road, Abeokuta, Nigeria \\ ${ }^{3}$ Department of Medical and Parasitology, Sacred Heart Hospitals, Lantoro, Abeokuta, Nigeria \\ ${ }^{4}$ Department of Physics, Covenant University, PMB 1023, Ota, Ogun State, Nigeria \\ ${ }^{5}$ Department of Mechanical Engineering Science, University of Johannesburg, Auckland Park Kingsway Campus, \\ Johannesburg 2006, South Africa
}

Correspondence should be addressed to Anuoluwa Abimbola Akinsiku; anu.akinsiku@covenantuniversity.edu.ng

Received 7 August 2017; Accepted 27 November 2017; Published 1 January 2018

Academic Editor: Vijaya Kumar Rangari

Copyright (C) 2018 Anuoluwa Abimbola Akinsiku et al. This is an open access article distributed under the Creative Commons Attribution License, which permits unrestricted use, distribution, and reproduction in any medium, provided the original work is properly cited.

In the quest for environmental remediation which involves eco-friendly synthetic routes, we herein report synthesis and modeling of silver nanoparticles (Ag NPs) and silver/nickel allied bimetallic nanoparticles (Ag/Ni NPs) using plant-extract reduction method. Secondary metabolites in the leaf extract of Canna indica acted as reducing agent. Electronic transitions resulted in emergence of surface plasmon resonance in the regions of $416 \mathrm{~nm}(\mathrm{Ag} \mathrm{NPs})$ and $421 \mathrm{~nm}$ (Ag/Ni NPs) during optical measurements. Further characterizations were done using TEM and EDX. Antimicrobial activity of the nanoparticles against clinical isolates was highly significant as $P<0.05$. These findings suggest application of Ag NPs as antibacterial agent against E. coli, S. pyogenes, and antifungal agent against $C$. albicans. Possible antibacterial drugs against $S$. pyogenes and E. coli can also be designed using Ag/Ni nanohybrid based on their strong inhibition activities. Similarly, the enhanced SPR in the nanoparticles is suggested for applications in optical materials, as good absorbers and scatters of visible light. Theoretical model clarified that the experiment observation on the relationship between metallic nanoparticles penetration through peptidoglycan layers and the activeness of microbial species depends on the nature of the nanoparticles and pore size of the layer.

\section{Introduction}

Recently, paradigm shift in technology has led to the synthetic protocols involving application of green chemistry, part of environmental remediation, encompassing use of biomaterials because of their eco-friendliness. The use of biological materials as sensors, information storage devices, and bimolecular array is on the increase. No doubt, novel characteristics are possessed by materials on nanometre scale, as this creates special interest which is applicable virtually to every aspect of life including medicine, agriculture, and polymer industry among others [1]. There is a growing interest in magnetic NPs of nickel origin due to their superior magnetic characteristics which has a useful application in medicine (as magnetic drug delivery) and therapeutics [24]. Imran Din and Rani [5] reviewed progress in the "green" protocols for the syntheses and stabilization of nickel and nickel oxide nanoparticles when Azadirachta indica and Psidium guajava leaves were utilized in the synthesis of $\mathrm{NiO}$ and Ni nanoparticles with an average size of $17-77 \mathrm{~nm}$. Facecentered cubic Ni NPs were reported by Chen et al. in which $\mathrm{Ni}\left(\mathrm{NO}_{3}\right)_{2}$ was reduced with Medicago sativa (alfalfa) 
extract. Ni NPs were also synthesized by Chen et al. with the leaf extract of Ocimum sanctum as reducing and stabilizing agents: hydrated electrons of $O$. sanctum aqueous leaf extract were considered to have reduced $\mathrm{Ni}(\mathrm{II})$ ions into $\mathrm{Ni}(0)[6,7]$.

Biosynthesized conjugated bimetallic nanoparticles are now used in biomedical field, imaging, luminescence tagging, labeling, and drug delivery due to their compatibility in in vivo screening [8]. Glucose-capped nickel nanoparticles (GNi NPs) were synthesized by Vaseem et al. via aqueous solution method in which glucose bifunctioned as capping agent and a reducing agent [9]. Canna indica (Linn.), commonly known as Indian shot belonging to the family Cannaceae is a medicinal plant of diverse uses. The herb consists of rhizomatous root stocks; reddish or yellowish showy flowers, which encompass a variable number of rounds; and shiny black seeds. In folkloric medicine, root decoction is used for the treatment of fever, dropsy, and dyspepsia [10]. Seed juice is used to relieve ear aches. Many varieties of $C$. indica are grown in the gardens and around houses for beautification. Ethnomedical use of $C$. indica leaves include antimicrobial, analgesic, and anthelmintic activities [11]. Research has shown that extraction of $C$. indica rhizomes using water was effective for HIV-1 reverse transcriptase inhibitory activity [12].

From survey, biological syntheses of nanomaterials make use of bacteria, yeasts, fungi, and algae (microorganisms). The use of plants or plant extracts for metal and metal hybrid nanoparticles synthesis is currently a new research focus that has gained wide acceptance [13]. As the demands for commercial nanoparticles are on the increase due to their wider applications in many fields, plant mediated green synthesis presents a cost-effective alternative method that is eco-friendly and sustainable [14]. The technique provides stable nanoparticles dispersions that resist aggregation in biological media and have high resistance to oxidation which is of significant importance [15]. Consequently, there is a need to solve public health problem of drug resistance by the disease causing microbes; new drug procedure needs to be adopted. It is noteworthy that Nigeria is endowed with natural biodiversity whose potential for developing novel health care and active drug candidates through green method has been underutilized. Plant extract with adequate phytochemicals has been confirmed to be faster in initiating bioreduction compared to microbes and the conventional chemical methods [16].

Quite a number of literatures have reported syntheses of allied silver-nickel nanoparticles using various chemical methods. Adekoya et al. [17] synthesized optically active fractal seed mediated silver-nickel bimetallic nanoparticles by chemical method; nevertheless, no investigations were carried out using Canna indica green-mediated route technique for the synthesis of $\mathrm{Ag} / \mathrm{Ni}$ bimetallic nanoparticles. In view of the potential of Ag and Ni NPs having good antibacterial activity against some pathogenic organisms [18] and their optical properties as a result of shift of surface plasmon resonance wavelength $\left(\lambda_{\mathrm{SPR}}\right)$ to a longer wavelength based on particle size [19], we report facile green synthetic methodology and theoretical modeling of silver and silver/nickel hybrid nanoparticles that entails in situ reduction of aqueous
$\mathrm{Ag}(\mathrm{I})$ and $\mathrm{Ni}(\mathrm{II})$ ions. The phytochemicals present in the aqueous leaf extract of Canna indica were considered to act as reducing/capping agents. UV-Visible spectrophotometer was used to monitor the optical properties; morphological characterization, size determination, elemental analysis, and antimicrobial screening of the biosynthesized nanoparticles were also carried out.

\section{Experimental Details}

2.1. Materials. Canna indica leaf extract (Indian shot), Whatman number 1 filter paper, distilled deionized water, silver nitrate $\left(\mathrm{AgNO}_{3}\right)$, and nickel nitrate hexahydrate $\mathrm{Ni}\left(\mathrm{NO}_{3}\right)_{2} \cdot 6 \mathrm{H}_{2} \mathrm{O}$, commercially obtained from SigmaAldrich Company, UK, were used as obtained.

2.1.1. Test Microorganisms. Freshly cultured clinical isolates of Escherichia coli, Pseudomonas aeruginosa (gramnegative bacteria), Staphylococcus aureus, Streptococcus pyogenes (gram-positive bacteria), Candida albicans, and Trichophyton rubrum (Fungi) were collected from the Department of Medical Microbiology and Parasitology, Sacred Heart Hospital, Lantoro, Abeokuta, in Nigeria.

2.1.2. Preparation of Leaf Extract. Indian shot plant was collected from a garden at Atan-Iju, Ogun State, Nigeria. Plant identification and authentication were carried out at Forest Research Institute of Nigeria (FRIN); voucher specimen FHI 109928 was deposited at the herbarium headquarters, Ibadan, Nigeria. Fresh leafy part of the plant was washed with distilled water, finely cut, and ground using mortar and pestle. It was then extracted at a ratio of $1: 5 \mathrm{wt} / \mathrm{v}$ using distilled deionized water, filtered with Whatman number 1 filter paper, and then kept at $4^{\circ} \mathrm{C}$. The filtrate was used for phytochemical screening and nanoparticle synthesis. The procedure is modified from previous work [20].

2.1.3. Phytochemical Screening of the Plant Extracts. Plant extract was screened to identify the phytochemicals present according to literature [21].

2.1.4. Syntheses of $A g$ and Ag/Ni Bimetallic Nanoparticles. Metallic nanoparticles were prepared by plant-extract reduction method with modification to previous work [22]. For the synthesis of Ag NPs, $10 \mathrm{~mL}$ of the $0.2 \mathrm{~g} / \mathrm{mL}$ aqueous filtrate of $C$. indica extract was added to $100 \mathrm{~mL}$ of varied concentrations of aqueous silver nitrate solution (0.5-2.0 mM). The reaction mixture was continuously stirred and gradually heated to $70^{\circ} \mathrm{C}$ on a hotplate. In the case of $\mathrm{Ag} / \mathrm{Ni}$ bimetallic nanoparticle synthesis, $20 \mathrm{~mL}$ of the plant extract was added to equal molar concentration mixture of $100 \mathrm{~mL}$ $\mathrm{AgNO}_{3}$ and $100 \mathrm{~mL} \mathrm{Ni}\left(\mathrm{NO}_{3}\right)_{2} \cdot 6 \mathrm{H}_{2} \mathrm{O}$ in a beaker. Precursor concentrations were varied between 0.5 and $3.0 \mathrm{mM}$. Initial colour of the mixture was noted. The resulting mixture was continuously stirred and gradually heated to $70^{\circ} \mathrm{C}$ until there was a change in colour. Bioreductions of $\mathrm{Ag}(\mathrm{I})$ ions to $\operatorname{Ags}(0)$ and $\mathrm{Ni}(\mathrm{II})$ to $\mathrm{Ni}(0)$ were monitored by taking samples at varied time intervals, using UV-Vis spectrophotometer (double beam Thermo Scientific GENESYS 10S model), 
starting from the 5 th minute until a noticeable colour change and appearance of surface plasmon resonance band (SPRB). Sample was placed in quartz cuvette, operated at a resolution of $1 \mathrm{~nm}$ so as to measure the absorbance.

2.1.5. Isolation of Metallic Ag and Ag/Ni Nanoparticles. The biosynthesized nanoparticles were collected by centrifugation using centrifuge model 0508-1, operated at $5000 \mathrm{rpm}$ for 30 minutes. For purification, the nanoparticles suspension was redispersed in distilled deionized water so as to remove the unbounded organics and finally centrifuged at 5,000 rpm for 10 minutes. The suspension was oven dried and kept in Eppendorf tubes for further characterizations.

\subsection{Characterization}

2.2.1. Optical Characterization. Optical properties of the prepared metallic nanoparticles were determined using a double beam Thermo Scientific GENESYS 10S UV-Vis spectrophotometer between 200 and $800 \mathrm{~nm}$ wavelength ranges. Absorbance measurement was carried out by placing each aliquot sample taken at time intervals in quartz cuvette $(1 \mathrm{~cm}$ path length), operated at a resolution of $1 \mathrm{~nm}$, using distilled deionized water as blank.

2.2.2. Structural Characterization. Structural, morphological characteristics and size determination of the particles were verified with Technai G2 transmission electron microscope (TEM) coupled with an energy-dispersive X-ray spectrometer (EDX), operated at an accelerating voltage of $200 \mathrm{KeV}$ and $20 \mu \mathrm{A}$ current. Samples for TEM analysis were prepared by drop-coating $\mathrm{Ag}$ and $\mathrm{Ag} / \mathrm{Ni}$ suspensions onto carbon-coated copper TEM grids. The films on the TEM grids were allowed to dry prior to measurement.

\subsection{Antimicrobial Activity}

2.3.1. Turbidity Standard for Inocula Preparation. McFarland standard on laboratory guidance was used for the standardization of organisms for susceptibility testing, using a modified method by British Society for Antimicrobial Chemotherapy. $\mathrm{BaSO}_{4}$ turbidity standard equivalent to 0.5 McFarland standards or its optical equivalent was used. The $0.5 \mathrm{McF}$ arland standard was prepared by adding $0.5 \mathrm{~mL}$ of $0.048 \mathrm{M} \mathrm{BaCl}_{2}$ of $(1.175 \% \mathrm{w} / \mathrm{v}) \mathrm{BaCl}_{2}$ in $2 \mathrm{H}_{2} \mathrm{O}$ to $99.5 \mathrm{~mL}$ of $0.18 \mathrm{M} \mathrm{H}_{2} \mathrm{SO}_{4}$ with constant stirring to maintain a suspension. The correct density of the turbidity standard was verified by a pg instrument UV-Vis spectrophotometer model T90+, with $1 \mathrm{~cm}$ light path, and matched cuvette to determine the optical density at a wavelength of $625 \mathrm{~nm}$. The acceptable range for the standard is $0.08-0.13$ for $0.5 \mathrm{McF}$ arland standard which is equivalent to $1.5 \times 10^{8}$ bacterial cells per $\mathrm{mL}$. The standard was distributed into screw cap tubes of the same size and volume, similar to method of growing or diluting the bacterial inocula. The tubes were tightly sealed to prevent loss by evaporation. They were then stored in the dark at room temperature. The turbidity standard was vigorously agitated on a vortex mixer before use. The standard remains potent for six months; appearance of large particles in the standard is an indication of expiration [23].

2.3.2. Preparation of Inocula. The microbial strains were propagated in Mueller Hinton broth, prepared by dispersing $5 \mathrm{~mL}$ of the prepared broth medium into each screw capped test tube, sterilized by autoclaving at $12^{\circ} \mathrm{C}$ for 15 minutes. The test tubes were cooled and kept in an incubator for 24 hours at $37^{\circ} \mathrm{C}$ in order to determine the sterility. The isolates were inoculated into the sterilized test tubes containing the medium and placed in an incubator overnight at $37^{\circ} \mathrm{C}$. Appearance of turbidity in broth culture was adjusted equivalent to $0.5 \mathrm{McF}$ arland standards. This was done to obtain standardized suspension. Sterile normal saline was added in order to obtain turbidity optically comparable to that of the $0.5 \mathrm{McF}$ arland standards or against a white background with contrasting black line. The McFarland 0.5 standard provided turbidity comparable to bacterial suspension containing $1.5 \times$ $10^{8} \mathrm{cfu} / \mathrm{mL}$ [24]. The suspension was used within 5 minutes so as to avoid population increase.

2.3.3. Sensitivity of Test Organisms. Antimicrobial properties of the biosynthesized nanoparticles were investigated in the form of sensitivity testing, using modified version of the method described by Aida [25]. The test organisms were collected on sterile agar slant and incubated at $37^{\circ} \mathrm{C}$ for 24 hours. The following biochemical analyses were carried out on the bacteria test organisms: sugar fermentation, citrate utilization, oxidase reaction, Voges-Proskauer, methyl red, capsule staining, spore staining, motility, indole test, urease test, hydrogen sulphide test, gelatin liquefaction, and gram staining. Conversely, the fungus Candida albicans was identified by gram staining, germ tube test, sugar fermentation, and assimilation tests. Trichophyton rubrum (fungus) was identified macroscopically and microscopically using lactophenol cotton blue stains. These were then kept as stock culture on slant in the refrigerator at $4^{\circ} \mathrm{C}$. The procedure was in agreement with recommended standards of National Committee for Clinical Laboratory Standards (NCCLS) [24].

2.3.4. Agar Well Diffusion Method. Antibacterial activity of synthesized nanoparticles was evaluated by the well plate agar diffusion method as described in the Aida modified method [25]. The microbial cultures were adjusted to 0.5 McFarland turbidity standards and inoculated on Muller-Hinton agar plate of diameter $9 \mathrm{~cm}$. The plate was flooded with each of the standardized test organisms $(1 \mathrm{~mL})$ and then swirled. Excess inoculum was carefully decanted. A sterile cork borer was used to make wells ( $6 \mathrm{~mm}$ in diameter) on the agar plates. Aliquots of the nanoparticle dilutions $(0.1 \mathrm{~mL})$ were reconstituted in 50\% DMSO at concentrations of $100 \mathrm{mg} / \mathrm{mL}$ and applied on each of the wells in the culture plates previously inoculated with the test organisms. However, each extract was tested in duplicate with $0.1 \mathrm{~mL}$ of $5 \mu \mathrm{g} / \mathrm{mL}$ ciprofloxacin as positive control for bacteria and fluconazole as positive control for fungi. These were then left on the bench for 1 hour for proper diffusion of the nanoparticles [24]. Thereafter, the plates were incubated at $37^{\circ} \mathrm{C}$ for 24 hours for bacteria and 


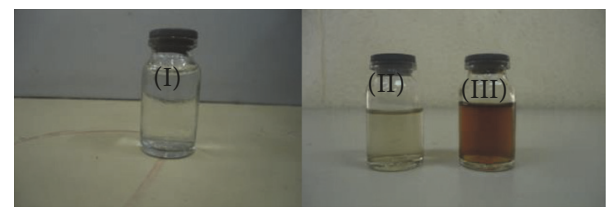

(i) $\mathrm{AgNO}_{3}$ solution

(ii) $\mathrm{AgNO}_{3}$ solution with extract before reduction

(iii) Final silver dispersion formed after reduction

(a)

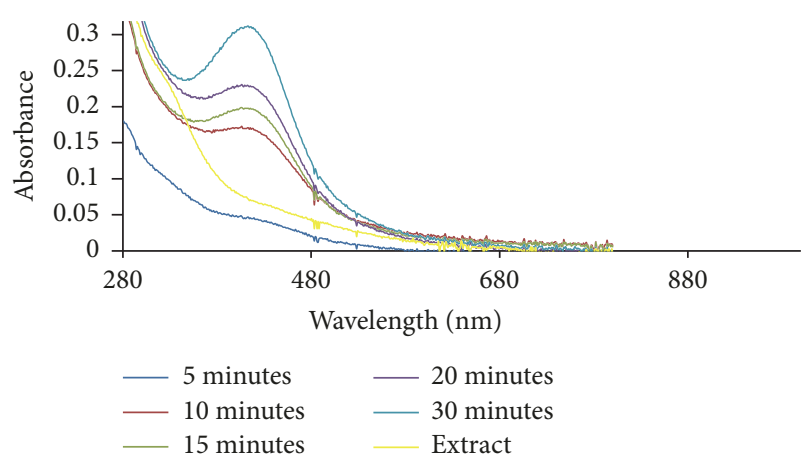

(c)

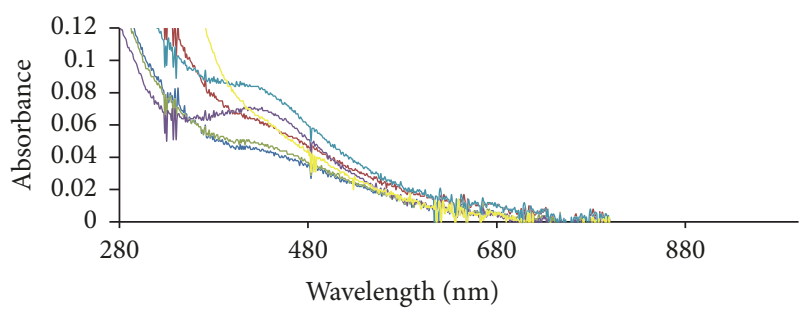

$\begin{array}{ll}-10 \text { minutes } & -45 \text { minutes } \\ -15 \text { minutes } & -1 \text { hour } \\ 30 \text { minutes } & \text { Extract }\end{array}$

(b)

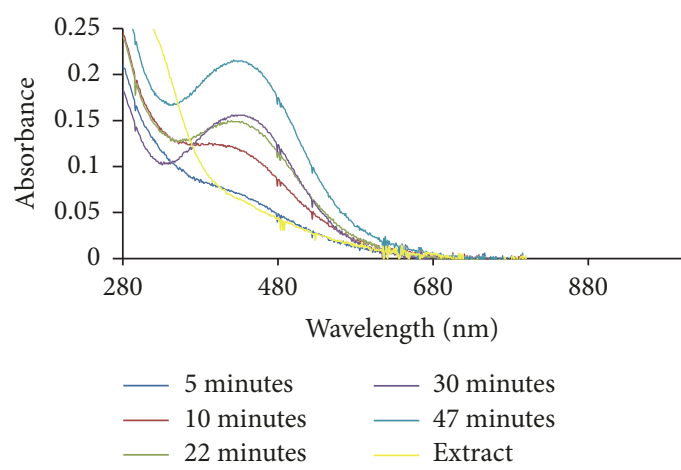

(d)

Figure 1: (a) Colour dispersion before and after nanoparticles formation, UV-Vis spectra of Ag NPs prepared by reducing (b) $0.5 \mathrm{mM}$, (c) $1.0 \mathrm{mM}$, and (d) $2.0 \mathrm{mM}$ precursor solutions using the extract of $C$. indica at $70^{\circ} \mathrm{C}$.

yeast and at $28^{\circ} \mathrm{C}$ for 72 hours for T. rubrum. Antimicrobial activity was determined by measuring the zone of inhibition around each well (excluding the diameter of the well) for nanoparticles obtained from the plant extract. Duplicate tests were conducted against each organism and significant growth inhibitions were found using analysis of variance (ANOVA), SPSS statistical tool.

2.3.5. Minimum Inhibitory Concentration (MIC). Serial dilution method was employed according to CLSI guidelines. Sterile test tubes (12) were arranged in a rack. $1 \mathrm{~mL}$ of sterile nutrient broth was added to tube labeled 2 to $10.1 \mathrm{~mL}$ of known nutrients broth concentration was added to tubes 1 and 2. Afterwards, serial doubling dilution from tube 2 to tube 10 was made, while the remaining $1 \mathrm{~mL}$ was discarded. $1 \mathrm{~mL}$ of ciprofloxacin was added to tube 11 (positive control) and water to tube 12 (negative control). $1 \mathrm{~mL}$ of $0.5 \mathrm{McF}$ arland was added overnight and broth culture to all the tubes and then covered. The experiment was incubated overnight at $37^{\circ} \mathrm{C}$ and observed for the highest dilution showing no turbidity. The zone of inhibition was then verified and interpreted according to CLSI guidelines [26]; the MIC was determined.

2.3.6. Minimum Bactericidal Concentration (MBC) and Minimum Fungicidal Concentration (MFC). MBC, the lowest concentration of antibiotic agent that kills at least $99.9 \%$ of the organisms, was determined by using Doughari et al. method. $0.5 \mathrm{~mL}$ of the sample was removed from those tubes from MIC which did not show any visible sign of growth and inoculated on sterile Mueller Hinton agar by streaking. The plates were then incubated at $37^{\circ} \mathrm{C}$ for 24 hours. The concentration at which no visible growth was seen was recorded as the minimum bactericidal concentration (MBC). For MFC, $0.5 \mathrm{~mL}$ of the sample which showed no visible sign of growth during MIC screening was taken from the test tubes and then inoculated on sterile potato dextrose agar by streaking. The plates were then incubated at $37^{\circ} \mathrm{C}$ for 24 hours. The concentration at which no visible growth was seen was recorded as the minimum fungicidal concentration [27].

\section{Results and Discussion}

3.1. Optical Properties of the Metallic Nanoparticles. UV/Visible spectra of the biosynthesized silver nanoparticles (Ag NPs) and silver-nickel (Ag/Ni) bimetallic nanoparticles (Ag/Ni NPs) as a result of photon absorption by their solutions are displayed in Figures 1-3. There was a noticeable colour change from light brown to deep brown which signalled formation of nanoparticles (Figure 1(a)). This is as a result of electronic transitions within the structures of $\mathrm{Ag}$ and $\mathrm{Ag} / \mathrm{Ni}$ nanoclusters as they interacted with light. The electronic transitions within the structures of metallic nanoparticles resulted in emergence of surface plasmon resonance (SPR) which increased in peak intensity and confirmed Ag and Ag/Ni NPs formation [28]; bioreduction of $\mathrm{Ag}^{+}$to $\mathrm{Ag}^{0}$ is an indication for potential application as excellent absorbers of visible light scatter and absorbers. 


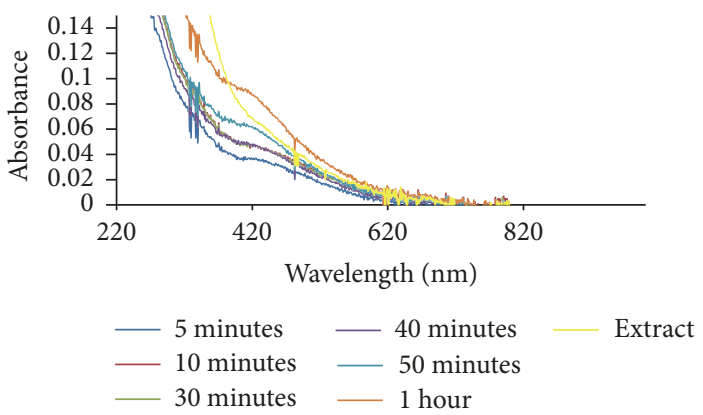

(a)

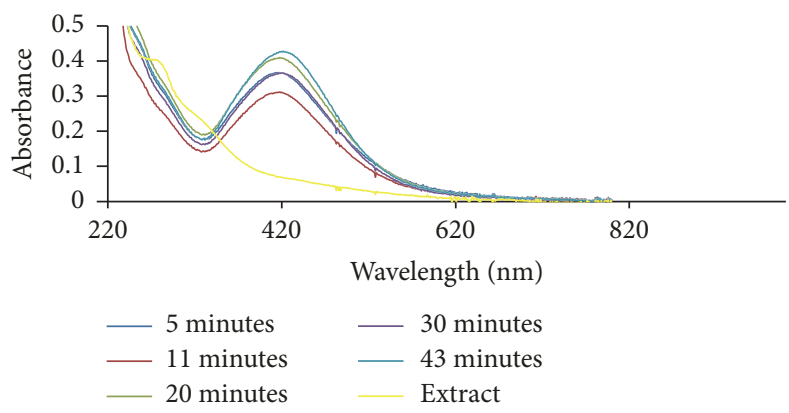

(c)

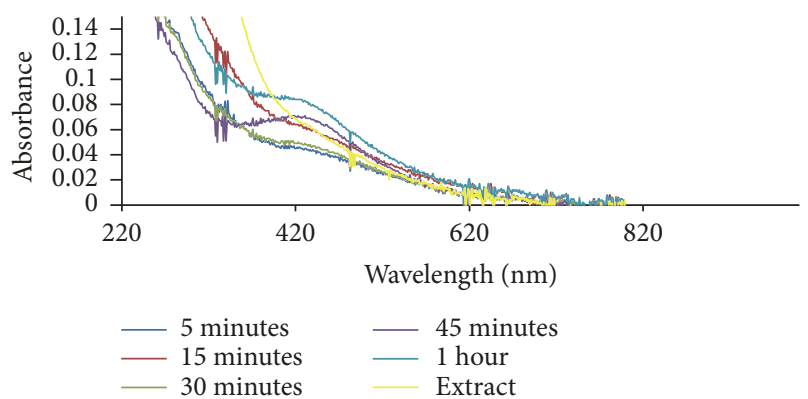

(b)

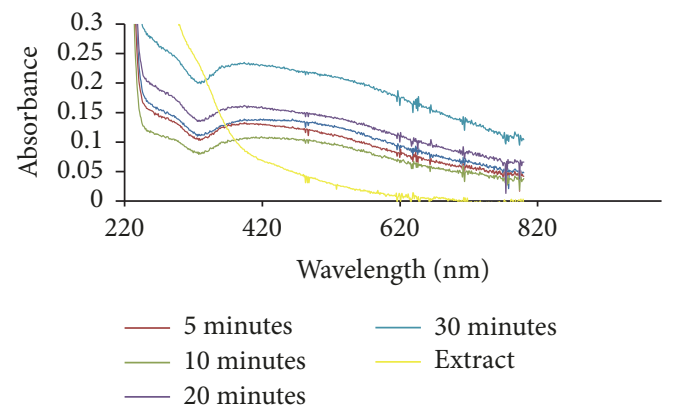

(d)

Figure 2: UV-Vis spectra of Ag/Ni bimetallic nanoparticles prepared by reducing (a) $0.5 \mathrm{mM}$, (b) $1.0 \mathrm{mM}$, (c) $2.0 \mathrm{mM}$, and (d) $3.0 \mathrm{mM}$ solutions using the extract of $C$. indica leaves at $70^{\circ} \mathrm{C}$. The blue curve represents surface plasmon resonance after 30 minutes.

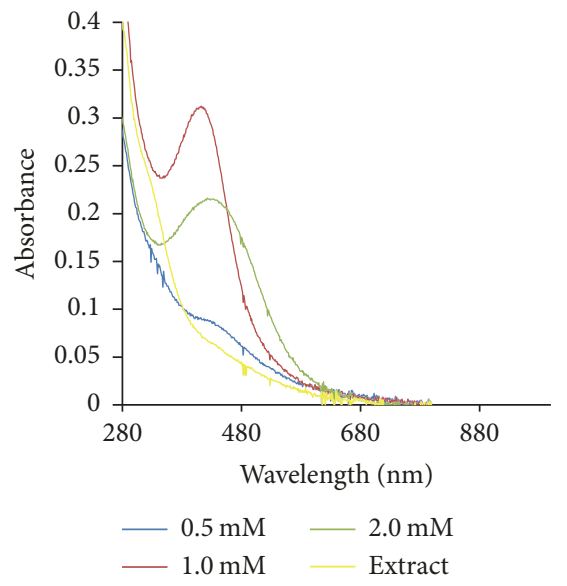

(a) Growth comparison in C. indica influenced Ag NPs prepared using varied precursor solution concentrations at $70^{\circ} \mathrm{C}, 30$ minutes

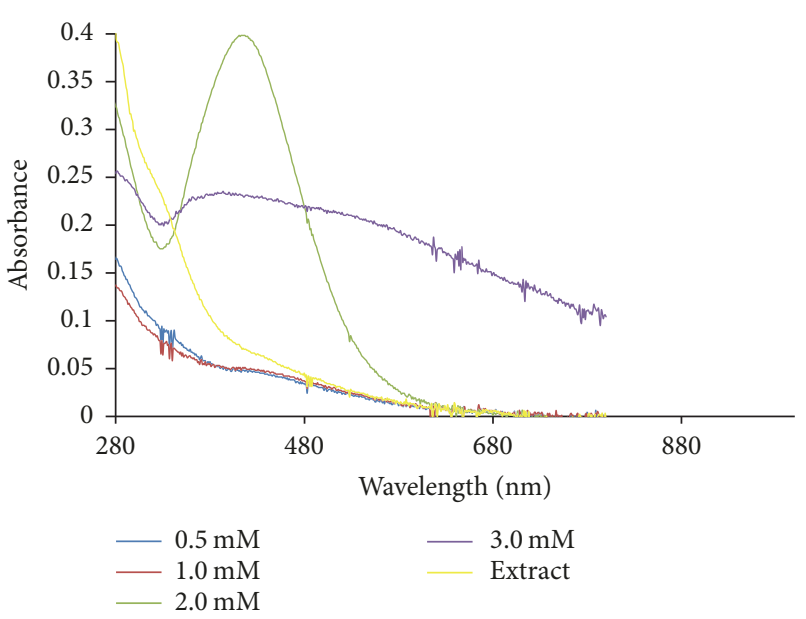

(b) Growth comparison in Ag-Ni bimetallic nanoparticles using the extract of C. indica at $70^{\circ} \mathrm{C}, 30$ minutes

Figure 3

Ag NPs formation had maximum absorption in the visible region with absorption wavelength of $416 \mathrm{~nm}$ and maximum intensity of 0.312 a.u. There was electron confinement effect when $1.0 \mathrm{mM} \mathrm{AgNO}$ was reduced, and this culminated in sharp peaks and strong intensity observed. Intensity of absorption in the hybrid nanoparticles prepared from $2.0 \mathrm{mM}$ precursor solution was in contrast to the maximum intensity of absorption noticed in the corresponding monometallic Ag NPs. In the bimetallic Ag/Ni NPs, there were narrow absorption spectra which increased in peak intensity without any shift in wavelength $(421 \mathrm{~nm})$. Hence, this signified presence of spherically shaped nanoparticles. Moreover, surface of the hybrid nanoparticles in Figure 2(c) is proposed to be enriched with silver, optically enhanced by nickel which is in line with previous work [29]. The observed narrow peak also depicted confinement of excitons in the nanoparticles as shown in Figures 1(c) and 2(c). Broad band in absorption wavelength between 400 and $450 \mathrm{~nm}$ in other 
nanobimetallic solutions of $0.5,1.0$, and $3.0 \mathrm{mM}$ precursor mixture suggested aggregation and polydispersed structures [30] and this could be as a result of interaction between solute and solvent, hereby reducing the structural resolution and maximum energy of the reaction. The observed spectra overlap at 20th and 30th minute with no further changes in intensity indicating reaction completion. In $\mathrm{Ag} / \mathrm{Ni}$ hybrid nanoparticles formation, an unprecedented bioreduction feature was observed, resulting in nucleation and growth of the nanoparticles within 5 minutes of reaction in all the concentrations. This observation was different in the case of monometallic Ag NPs in which nucleation and formation were delayed till 20 minutes in $0.5 \mathrm{mM}$ metal precursor but was relatively faster at higher precursor solution concentrations $(1.0$ and $2.0 \mathrm{mM})$. The belated onset growth and reduction of $0.5 \mathrm{mM}$ precursor suggested diverse mechanistic character in the formation of nanoparticles [31].

However, presence of nickel (Ni) in the hybrid synthesis of course led to a red shift in the absorbance wavelength from 416.0 to $421 \mathrm{~nm}$, as observed in the reduced $2.0 \mathrm{mM}$ precursor solution of $\mathrm{Ag} / \mathrm{Ni}$ NPs. There was an obvious increase in intensity of absorption when compared with the corresponding Ag NPs. Growth comparison and optimum concentration for Ag NPs and Ag/Ni bimetallic synthesized at $70^{\circ} \mathrm{C}$ are displayed in Figures 3(a) and 3(b), respectively. Size increase due to red shift of absorption wavelength with an enhanced surface plasmon resonance was noted for application in biodiagnostic, optical materials, optoelectronics, and good absorbers of visible light and scatters [32].

Biomolecules which acted as the reducing and capping/stabilizing agents for the newly formed nanoparticles were considered to be adequate as a result of unprecedented fast and successful bioreduction [33]. It is noteworthy that Canna indica leaf extracts contained the following secondary metabolite: alkaloids, glycosides, and terpenoids were identified in the water extract (Table 1). Tannins, flavonoids, and saponins were also detected in addition when leaf part of the plant was extracted with methanol (Table 1). These were confirmed thorough phytochemical screening. Despite choice of water as the extraction solvent ("green" part of the study) with limited amount of phytochemicals observed compared with methanol extract, the bioreduction and nanoparticles formation were successful. Proposed mechanisms of nanoparticles formation are presented in Schemes 1-6.

\subsection{Proposed Mechanisms of Reactions. See Schemes 1-6.}

3.3. Morphology of the Metallic Nanoparticles. Particle size distribution histogram and TEM image of the biosynthesized $\mathrm{Ag} / \mathrm{Ni}$ bimetallic nanoparticles are depicted in Figures 4(a) and $4(\mathrm{~b})$, respectively. Other representative TEM images are shown in Figures 5(a) and 5(b). TEM image revealed quasi-spherical shapes of average diameter of $9.10 \pm 1.12 \mathrm{~nm}$ for Ag NPs, while micrograph of the bimetallic Ag/Ni NPs revealed different shapes: cube with truncated/irregular edges plausibly due to the effect of Ostwald ripening and multiply twinned hybrid after 30 minutes of the reaction with a mean particle size of $9.86 \pm 2.37 \mathrm{~nm}$ [34]. Structural elucidation from TEM image also revealed formation of core-shell $\mathrm{Ag} / \mathrm{Ni}$ nanoparticles. The denser silver particles were distinctly visible in the TEM image. The Ag nanoparticles appeared as a dark core with Ni particles appearing less dark on the surface (Figure 2(d)). EDX analysis showing elemental compositions confirmed presence of nickel in the nanohybrid which was silver/nickel enriched with organic capping agent of carbon content which originated from plant extract (Figure 6(b)).

This finding is unique in biosynthesis of nanoparticles. Related finding was reported by Mntungwa et al. [35]; nevertheless, chemical method was applied to obtain the coreshell structure. Mechanism of the process could be explained as the ability of the plant extract to reduce the metal ions, followed by nucleation of metal atoms. Ostwald's ripening took place as a result of redissolution of high solubility and surface energy of smaller particles in the solution as the growth of larger particles continued more, as described by Lifshic and Slezov [36]. The growth pattern is considered to be anisotropic due to size increase of the NPs. Furthermore, in the mechanism, Ag (I) got reduced first because of its higher positive electrochemical potential than nickel which led to the formation of silver core [37].

\subsection{Antimicrobial Activity}

3.4.1. Antimicrobial Assay. Activity of the biosynthesized Ag NPs and Ag/Ni bimetallic nanoparticles based on size of zones of inhibition in millimetre $(\mathrm{mm})$ is shown in Figure 7. Agar diffusion test revealed that the prepared nanoparticles possessed both antibacterial and antifungal properties. The screened nanoparticles exhibited higher activities on all the test organisms at higher concentration of $3.0 \mathrm{mM}$ except $P$. aeruginosa in which low activity was recorded. Sensitivity testing of organisms (Agar diffusion test) in triplicate showed zones of inhibition. Mean zone of inhibition diameter ( $\mathrm{mm}$ ) \pm standard deviation is shown in Table 2. One-way analysis of variance (ANOVA) using SPSS statistical tool indicated that growth inhibition by the nanoparticles was significant at $P<0.05, F$-value 34.06 (Table 3 ).

Zones of inhibition recorded in agar well diffusion test led to the conduction of minimum inhibitory concentration (MIC), minimum bactericidal concentration (MBC) and minimum fungicidal concentration (MFC) tests. Results of MIC, MBC, and MFC tests are presented in Table 3. Interestingly, all prepared nanoparticles showed concentrationdependent inhibitory effects on the in vitro antimicrobial assay [38]. Highest activity of Ag NPs was on E. coli and C. albicans with MIC value of $12.5 \mathrm{mg} / \mathrm{mL}$ and $2.5 \mathrm{mg} / \mathrm{mL}$ (same value for $\mathrm{MBC}$ and $\mathrm{MFC}$ ), followed by $S$. aureus and $S$. pyogenes $(12.5 \mathrm{mg} / \mathrm{mL}$ value of $\mathrm{MIC}$ and $\mathrm{MBC})$. The activity was least on T. rubrum $(50 \mathrm{mg} / \mathrm{mL} \mathrm{MIC}, 100 \mathrm{mg} / \mathrm{mL}$ MFC). However, no detectable activity was found against $P$. aeruginosa. Higher activity was observed in Ag/Ni nanoparticles against $S$. pyogenes with MIC value of $6.25 \mathrm{mg} / \mathrm{mL}$ and $12.5 \mathrm{mg} / \mathrm{mL}$ MBC.

In hybrid $\mathrm{Ag} / \mathrm{Ni}$ nanoparticles, analysis of variance (ANOVA) using SPSS statistical tool indicated no significant difference in the concentrations as $P>0.05$, yet possessing better activity than its corresponding Ag NPs which was observed at different levels in the test organisms. Moreover, 


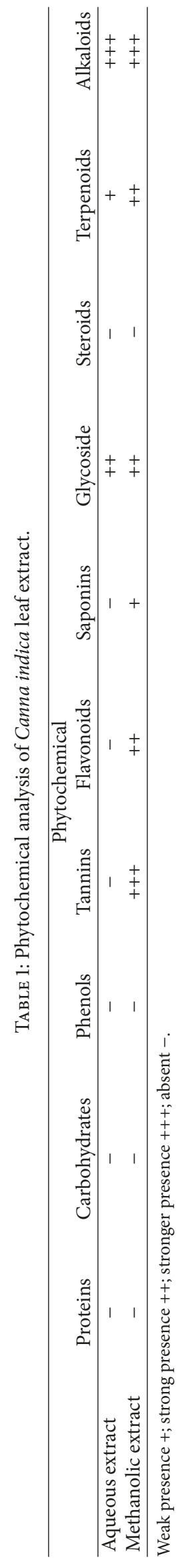




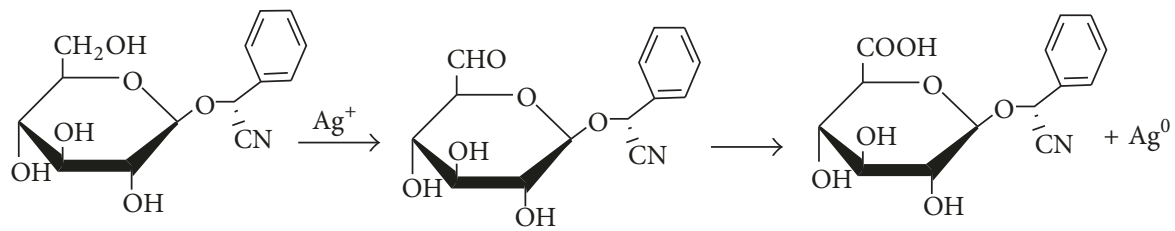

Scheme 1: Bioreduction of silver ion to silver nanoparticles by glycosides.

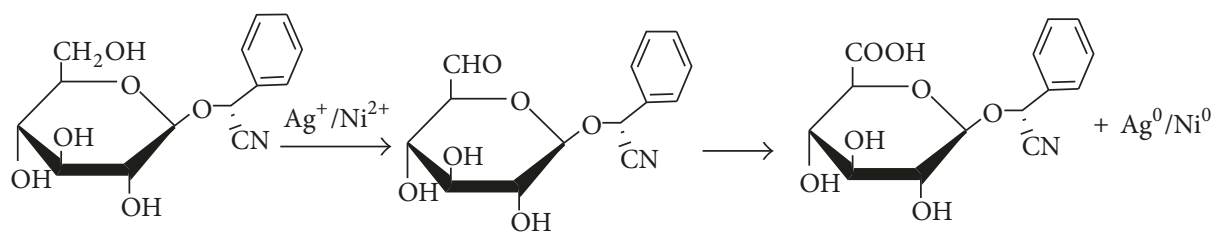

Scheme 2: Bioreduction of silver/nickel ions to silver/nickel nanoparticles by glycosides.<smiles>C=[N+]1CCCC1c1ccncc1</smiles>

SCHEME 3: Bioreduction of silver ion to silver nanoparticles by alkaloids.<smiles>C=[N+]1CCCC1c1ccncc1CN1CCCC1c1cccnc1</smiles>

Scheme 4: Bioreduction of silver/nickel ions to silver/nickel nanoparticles by alkaloids.<smiles>CC1CCC(C(C)C)C(O)C1</smiles>

Scheme 5: Bioreduction of silver ion to silver nanoparticles by terpenoids.<smiles>CC1CCC(C(C)C)C(OC(=O)C2C(C)CCC(C(C)C)C2O)C1</smiles>

SCHEME 6: Bioreduction of silver/nickel ions to silver/nickel nanoparticles by terpenoids. 


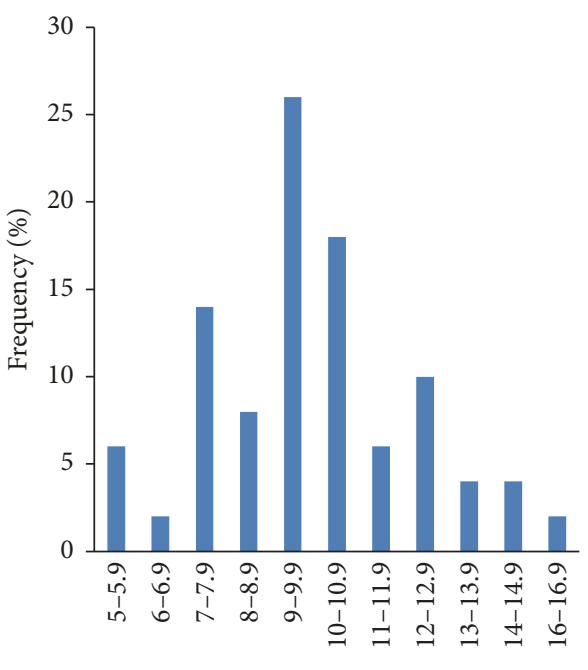

Particle size $(\mathrm{nm})$

(a)

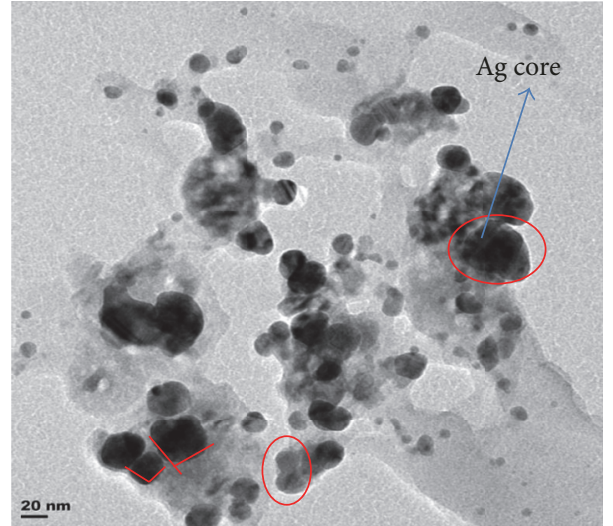

(b)

FIgure 4: (a) Particle size distribution histogram of Ag/Ni determined from TEM images. (b) Representative TEM image of the bimetallic $\mathrm{Ag} / \mathrm{Ni}$ NPs under $C$. indica influenced synthesis.

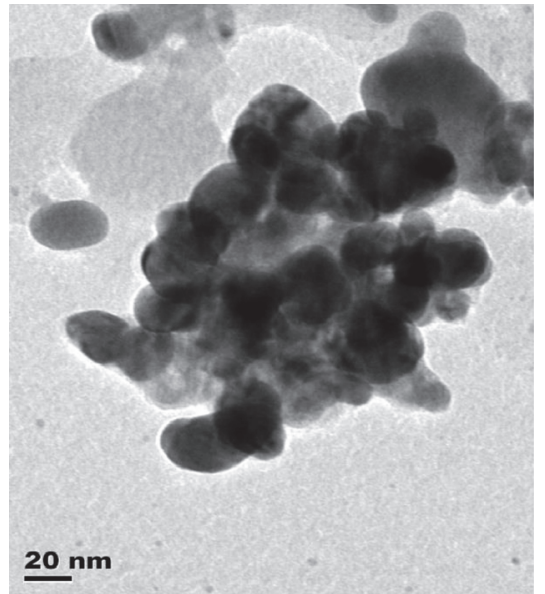

(a)

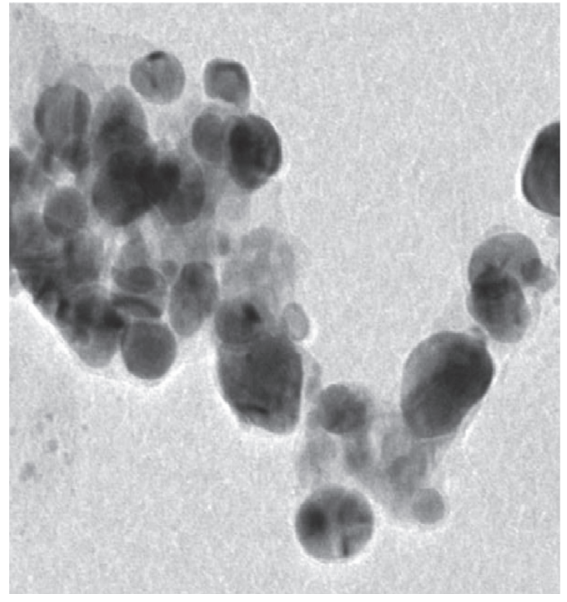

(b)

Figure 5: Representative TEM images of Ag/Ni bimetallic NPs derived from $\mathrm{C}$. indicia leaf extract.

these nanoparticles could not hinder the growth of $P$. aeruginosa. None of the as-synthesized nanoparticles was able to compete with ciprofloxacin and fluconazole (standards) in terms of activity. S. aureus, S. pyogenes, and E. coli showed similar behaviour relative to MIC and MBC, while $P$. aeruginosa was highly resistant. The metallic nanoparticles were more active on $C$. albicans than T. rubrum possibly because they were able to penetrate the thin peptidoglycan layer of the fungus with the outer membrane composed of phospholipids and lipopolysaccharides (LPS) of the $E$. coli (complex gram-negative bacterium). Not only were the bionanoparticles considered to have passed through thicker peptidoglycan cell wall layer which is accountable for rigidity and low activity in gram-positive bacteria, as detected in the
MIC test carried out on S. aureus and S. pyogenes [39], but, according to Marini et al., the observed growth inhibition in bacteria can also be related to the reaction of thiol groups present in bacteria protein with the release of $\mathrm{Ag}^{+}$which slowed down or changed the replication of DNA [40].

From the above, there is a need to affirm if the penetrations of the nanoparticle through the microbial samples influence its experimental result. Tan et al. [41] did the characterization of nanoparticle dispersion through red blood cell using the nanoparticle model. Through experimentation, the nanoparticle dispersion model was given as

$$
D_{r}=\frac{D-D_{0}}{d_{\text {layer }}^{2} \eta} .
$$




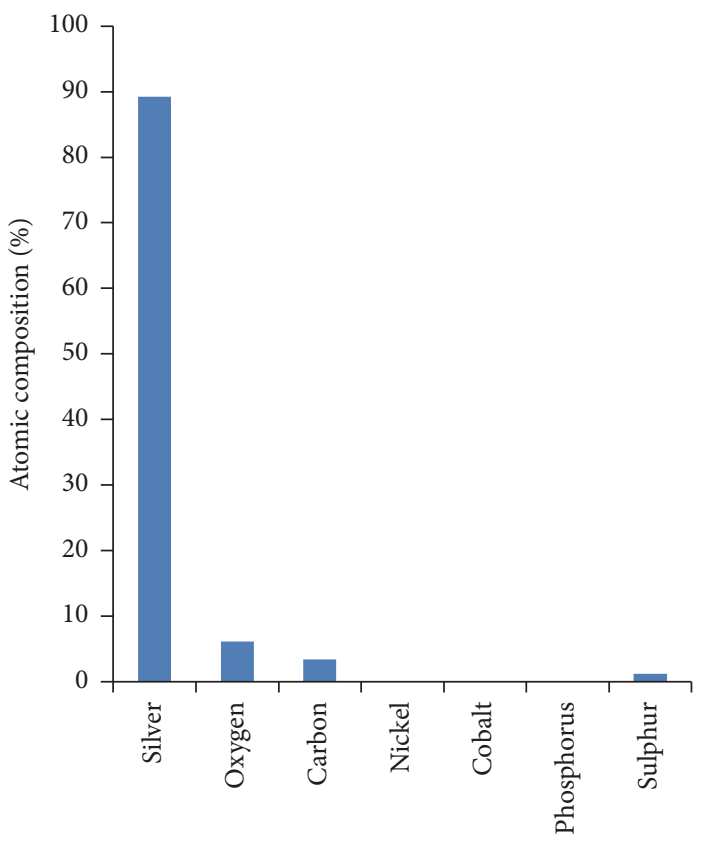

Element

(a) EDX showing atomic composition of elements present in Ag NPs

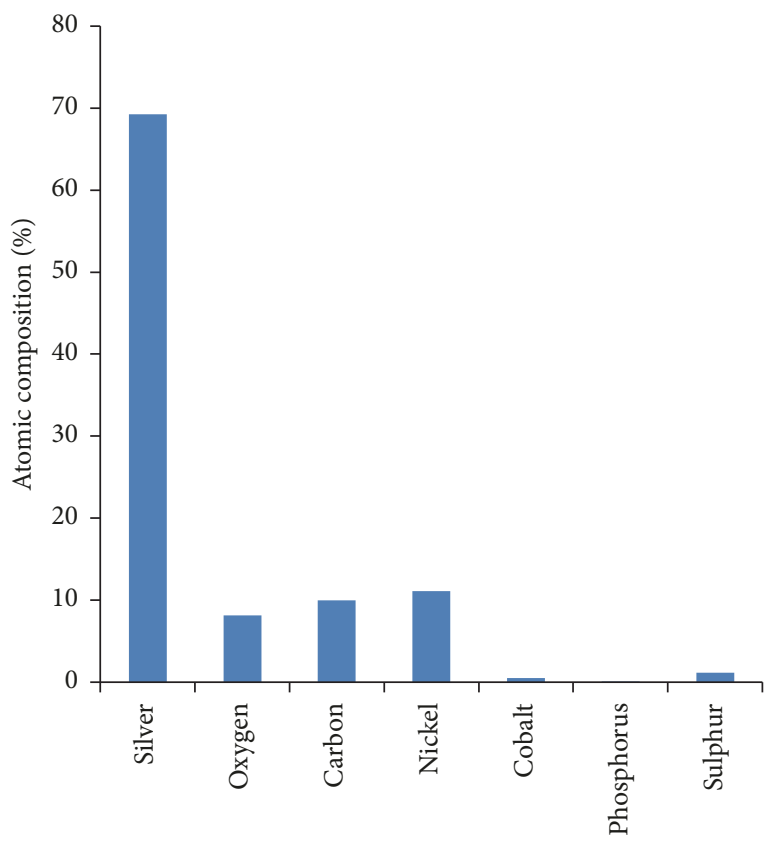

Element

(b) EDX showing atomic composition of elements present in $\mathrm{Ag} / \mathrm{Ni}$ bimetallic NPs

Figure 6

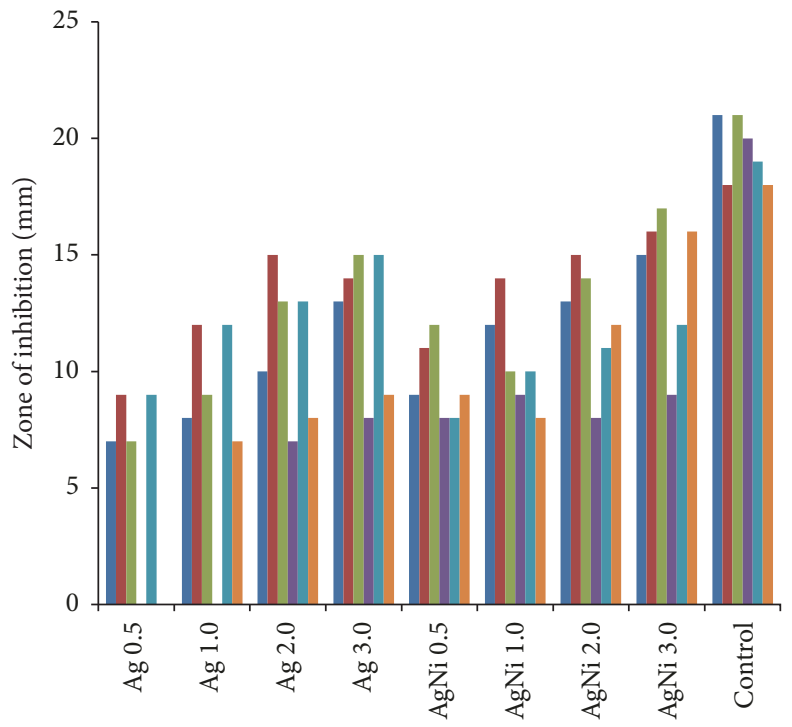

Precursor concentration (mM)

- Staphylococcus aureus

- Streptococcus pyogenes

- Pseudomonas aeruginosa

- Escherichia coli

- Candida albicans

- Trichophyton rubrum

FIgURe 7: Comparison of inhibition zones between Ag NPs and Ag-Ni bimetallic nanoparticles synthesized using C. indica leaf extract. 


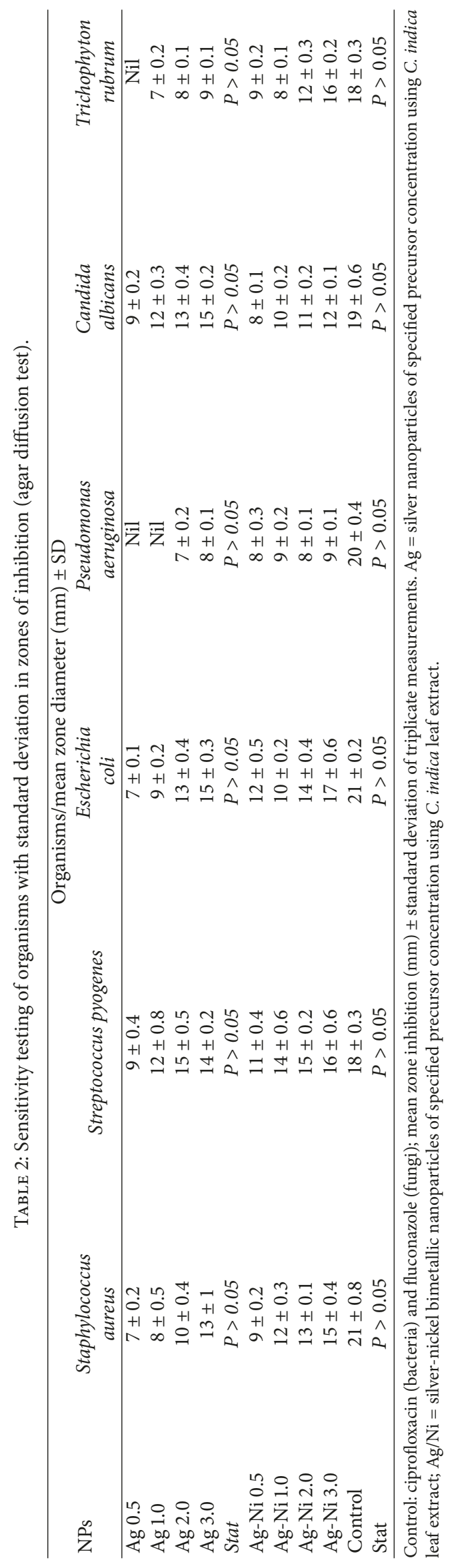




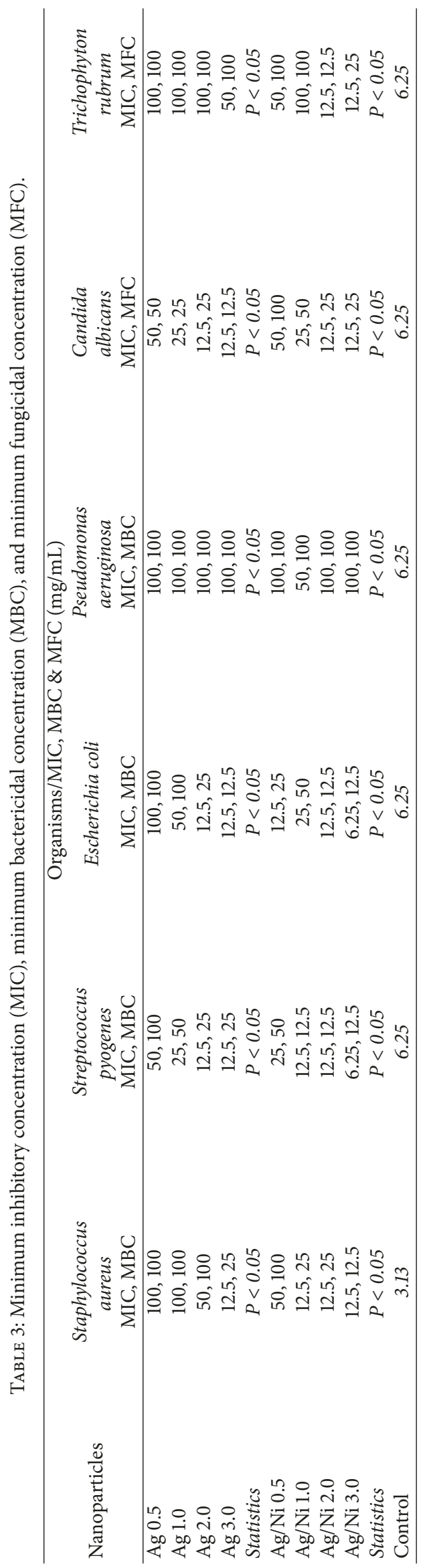


$D_{r}$ is the dimensionless dispersion rate, $D$ is the dispersion rate, $D_{0}$ is the dispersion tendency, $d$ is the cell/layer, and $\eta$ is the shear rate. Tan et al. [41] worked with the shear rate below $40 \mathrm{~s}^{-1}$ and above $200 \mathrm{~s}^{-1}$.

Kleinstreuer and $\mathrm{Xu}$ [42] hence gave $D_{0}$ for metallic nanoparticles penetration through the thin peptidoglycan layer as

$$
D_{0}=\frac{k_{B} T}{3 \pi \mu_{\mathrm{bf}} d_{p}},
$$

where $k_{B}$ is the Stefan Boltzmann constant, $T$ is the local temperature, $\mu_{\mathrm{bf}}$ is the base fluid viscosity, and $d_{p}$ is the particle diameter. From past experimentation, Benakashani et al. [43] found average particle size of Ag NPs using the Debye-Scherrer equation:

$$
d_{\text {nano }}=\frac{K \lambda}{\beta \cos \theta},
$$

where $d$ is the size of the Ag NPs which is about $20 \mathrm{~nm}, K$ is the Scherrer constant that ranges between 0.9 and $1, \lambda$ is the wavelength of the $\mathrm{X}$-ray source, in this case it ranges between 280 and $780 \mathrm{~nm}, \beta$ is the full width at the half maximum of the diffraction peak, and $\theta$ is Bragg's angle.

The basic condition for the metallic nanoparticle to go through the polymer matrix of the thin peptidoglycan layer is $d_{\text {nano }}<d_{\text {layer }}$. Hence,

$$
d_{\text {layer }}=d_{\text {nano }}+d_{o}
$$

The dimensionless dispersion of the metallic nanoparticle through the peptidoglycan layer is given as

$$
\begin{aligned}
D_{r} & =\frac{D}{\left(K^{2} \lambda^{2} / \beta^{2} \cos ^{2}(\theta)+2 K \lambda d_{0} / \beta \cos (\theta)+d_{0}^{2}\right) \eta} \\
& -\left(\frac{1}{\left(K^{2} \lambda^{2} / \beta^{2} \cos ^{2}(\theta)+2 K \lambda d_{0} / \beta \cos (\theta)+d_{0}^{2}\right) \eta}\right) \\
& \cdot\left(\frac{k_{B} T}{3 \pi \mu_{\mathrm{bf}} d_{p}}\right),
\end{aligned}
$$

where

$$
D= \begin{cases}\frac{1}{4} \cos \left(\frac{\pi d_{p}}{4}\right) & d_{p}<10^{-9} \\ 0 & \text { otherwise }\end{cases}
$$

When $D=0$, then the dimensionless dispersion becomes

$$
\begin{aligned}
D_{r} & \\
& =\left(\frac{1}{\left(K^{2} \lambda^{2} / \beta^{2} \cos ^{2}(\theta)+2 K \lambda d_{0} / \beta \cos (\theta)+d_{0}^{2}\right) \eta}\right) \\
& \cdot\left(\frac{k_{B} T}{3 \pi \mu_{\mathrm{bf}} d_{p}}\right) .
\end{aligned}
$$

Hence, the illustration of the two cases is shown in Figures $8(a)-8(d)$ and $9(a)-9(d)$.

The first case (i.e., (5)) was when the diameter of the metallic particle is equal to or less than $10^{-9} \mathrm{~m}$. At a constant Bragg's angle of $45^{\circ}$, the feature of the dispersion/wavelength trend (Figure 8(a)) is the same as results shown in Figures 2 and 3. This is the first evidence that the penetration of metallic nanoparticles through the thin peptidoglycan layer does not necessarily influence the efficiency of its constituents. Then in a case when the sizes of the nanoparticle are heterogeneous, we assumed Bragg's angle of the nanoparticle ranges between $-30^{\circ}$ and $30^{\circ}$ (Figure $8(\mathrm{~b})$ ). Five peaks appeared with the maximum peak at wavelength $340 \mathrm{~nm}$. The significance of this result can be seen in its effect in Figures 2(a)-2(d). A further analysis was conducted to see the features of the dimensionless dispersion of the nanoparticles when Bragg's angle of the nanoparticle ranges between $-45^{\circ}$ and $45^{\circ}$ (Figure $8(\mathrm{c})$ ). Fifteen peaks were observed showing the response or sensitivity of Bragg's angle to nanoparticle transport within multilayers. Then Bragg's angle when the nanoparticle range is between $-60^{\circ}$ and $60^{\circ}$ was considered (Figure $8(\mathrm{~d})$ ). Only two peaks were observed. Hence, the penetration of nanoparticle does not depict the activeness of the microbial samples in all cases which largely depend on the nature and pore size of the peptidoglycan layer.

The second case (i.e., (7)) was when the diameter of the metallic particle is greater than $10^{-9} \mathrm{~m}$ (Figures 9 (a)-9(d)). It was observed that the features of Figures 8 and 9 were the same. However, the dimensionless dispersion is very low.

\section{Conclusion}

Rapid, facile, and environmental-friendly syntheses of monometallic Ag NPs and Ag/Ni bimetallic nanoparticles using Canna indica leaf extract were successful via reduction of $\mathrm{AgNO}_{3}$ and $\mathrm{Ni}\left(\mathrm{NO}_{3}\right)_{2} \cdot 6 \mathrm{H}_{2} \mathrm{O}$ metal precursors. No doubt, the leaf extract acted as the reducing/capping agent. The metallic nanoparticles were characterized for their optical and morphological properties. Nucleation and onset growth which were considered to be by diffusion control and Ostwald's ripening commenced as early as 5 minutes. Ag NPs had maximum absorption in the visible region with absorption wavelength of $416 \mathrm{~nm}$. However, presence of nickel $(\mathrm{Ni})$ in the hybrid synthesis led to a red shift in the absorbance wavelength from 416 to $421 \mathrm{~nm}$ after 30 minutes of the reaction. TEM image revealed quasi-spherical shapes of average diameter $9.10 \pm 1.12 \mathrm{~nm}$ in Ag NPs while micrograph of the bimetallic Ag/Ni cluster revealed different 


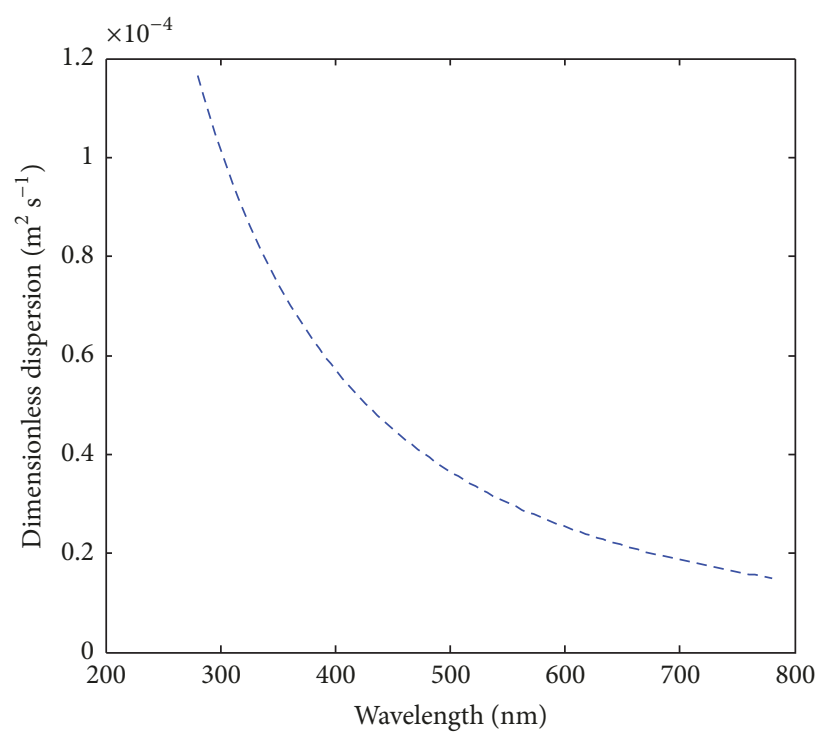

(a)

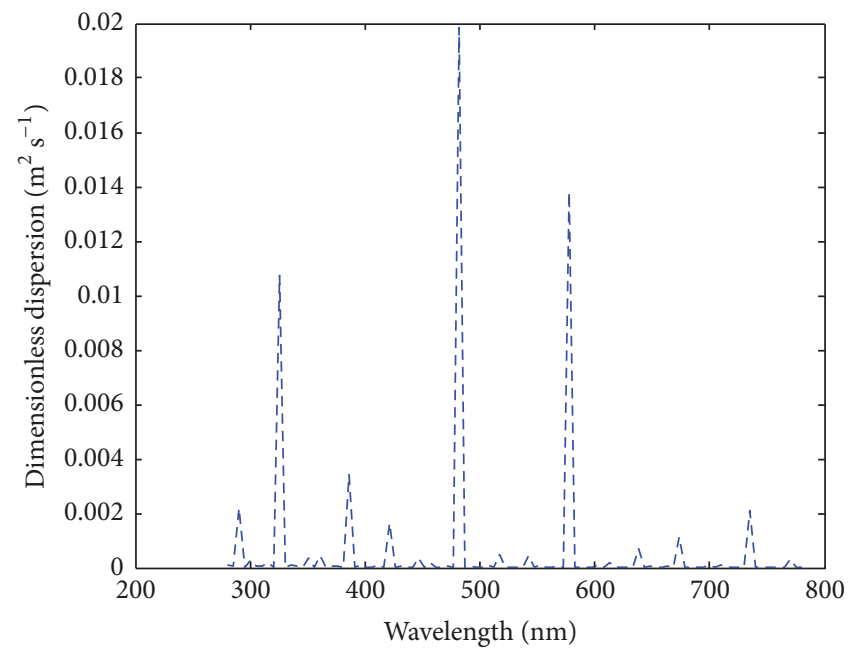

(c)

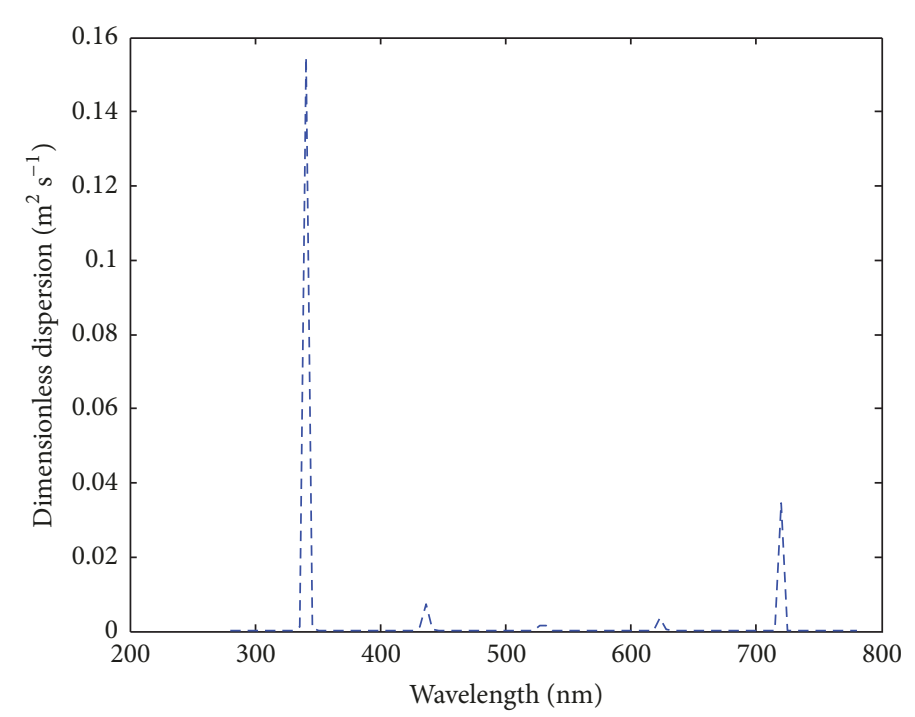

(b)

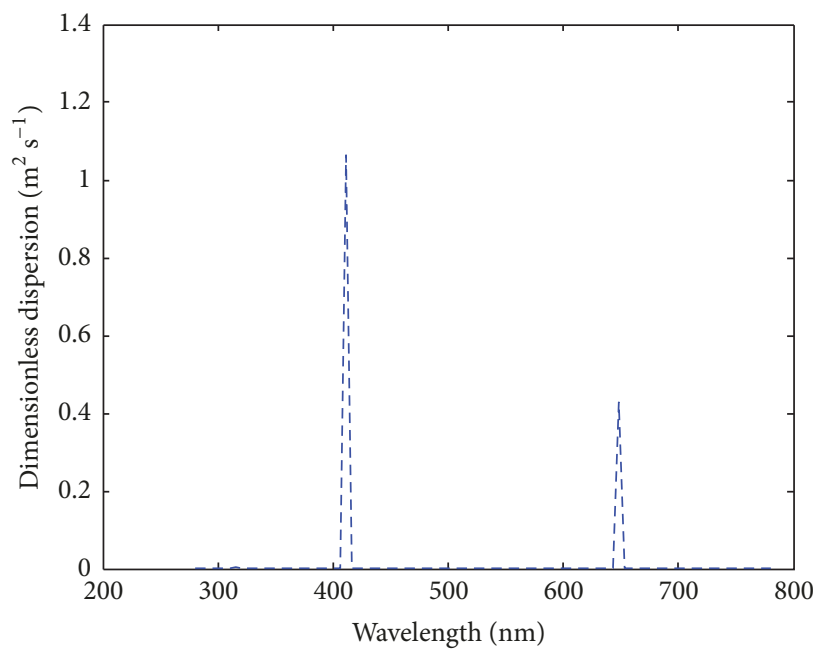

(d)

FIGURE 8: The dimensionless dispersion of the metallic nanoparticle under varying conditions (a) when Bragg's angle of the nanoparticle is strictly $45^{\circ}$; (b) when Bragg's angle of the nanoparticle ranges between $-30^{\circ}$ and $30^{\circ}$; (c) when Bragg's angle of the nanoparticle ranges between $-45^{\circ}$ and $45^{\circ}$; (d) when Bragg's angle of the nanoparticle ranges between $-60^{\circ}$ and $60^{\circ}$.

shapes: cube with truncated/irregular edges plausibly due to the effect of Ostwald ripening and multiply twinned hybrid after 30 minutes of the reaction with a mean particle size of $9.86 \pm 2.37 \mathrm{~nm}$. Structural elucidation from the TEM image also revealed formation of core-shell $\mathrm{Ag} / \mathrm{Ni}$ nanoparticles. The denser silver particles were distinctly visible in the TEM image. The Ag nanoparticles appeared as a dark core with $\mathrm{Ni}$ particles appearing less dark on the surface (Figure 2(d)). EDX analysis showing elemental compositions of the nanoparticles indicated that the nanohybrid was silver enriched with organic capping due to the composition of carbon content which originated from plant extract. Furthermore, $\mathrm{Ag} / \mathrm{Ni}$ bimetallic nanocluster exhibited better antimicrobial activity against the test pathogens than its corresponding monometallic Ag NPs. Hence, from the findings, $\mathrm{Ag} / \mathrm{Ni}$ NPs are potential antibacterial agents against E. coli and possible antifungal agents against $C$. albicans. Possible antibacterial drugs against $S$. pyogenes and $E$. coli can be designed using Ag-Ni nanohybrid, based on their strong inhibition activities observed. The observed enhanced SPR in the nanoclusters is noted for applications in optical materials, also as good absorbers of visible light absorber and scatters.

\section{Conflicts of Interest}

The authors declare no conflicts of interest in this research work. 


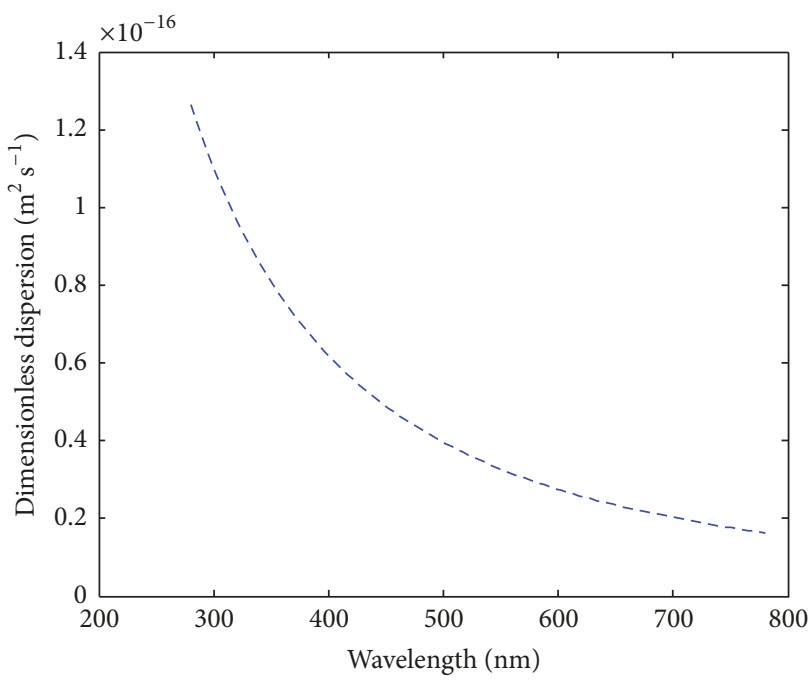

(a)

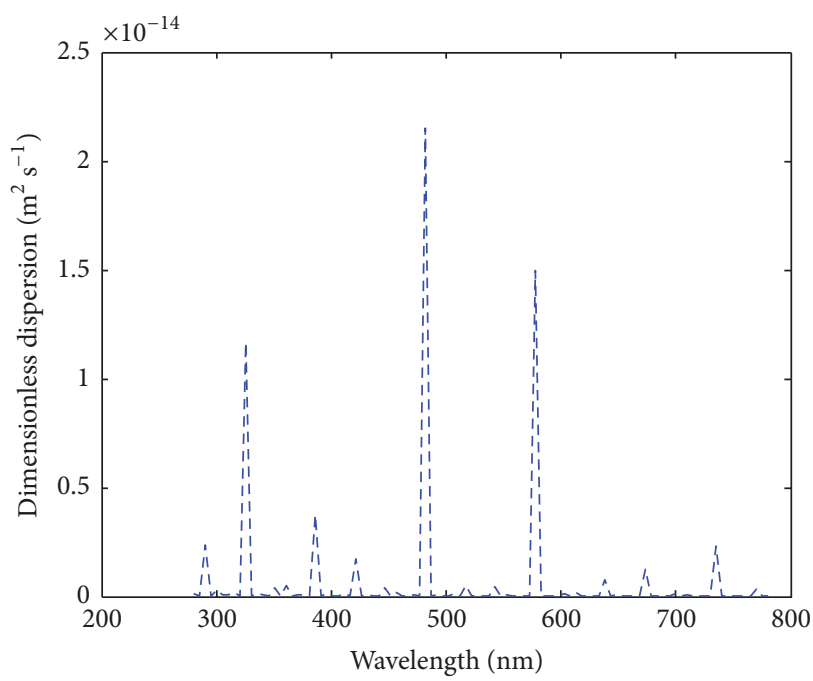

(c)

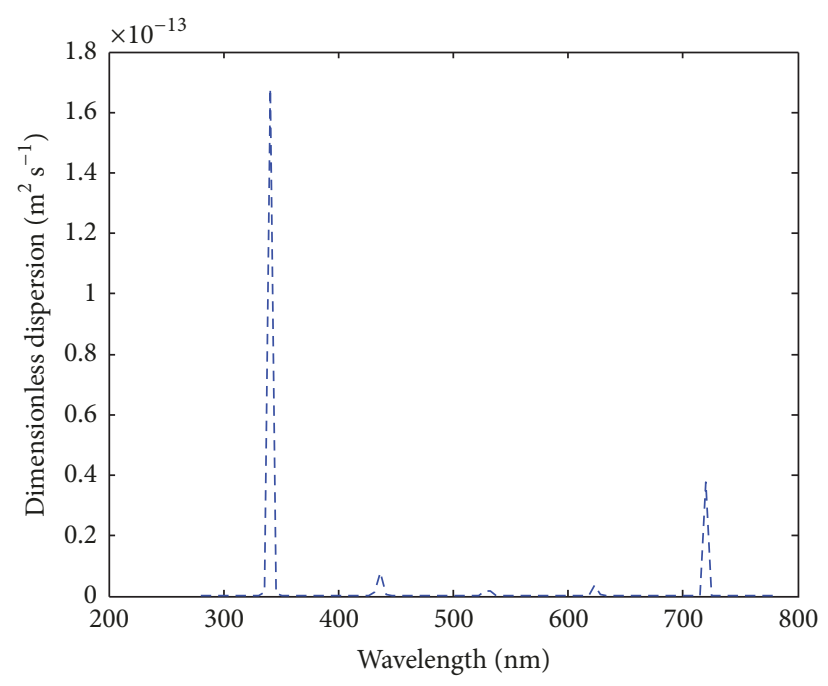

(b)

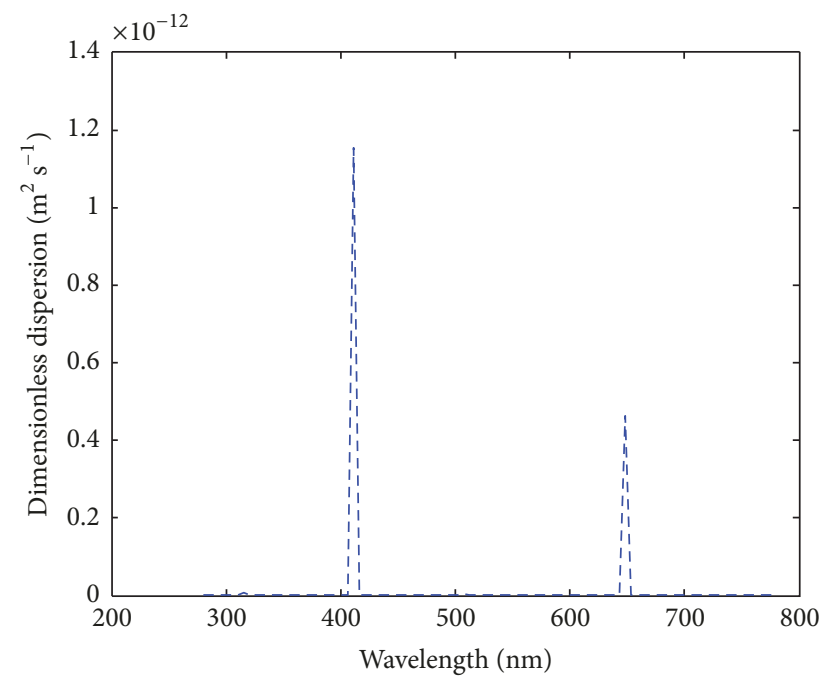

(d)

FIGURE 9: The dimensionless dispersion of the metallic nanoparticle under varying conditions at diameter greater than $10^{-9} \mathrm{~nm}(\mathrm{a})$ when Bragg's angle of the nanoparticle is strictly $45^{\circ}$; (b) when Bragg's angle of the nanoparticle ranges between $-30^{\circ}$ and $30^{\circ}$; (c) when Bragg's angle of the nanoparticle ranges between $-45^{\circ}$ and $45^{\circ}$; (d) when Bragg's angle of the nanoparticle ranges between $-60^{\circ}$ and $60^{\circ}$.

\section{Acknowledgments}

The authors are grateful to Mr. Olusola Rotimi of the University of Western Cape, Bellville Campus, Cape-Town, Mr. Shitole Joseph of iThemba Labs, and Mr. Olufemi Olaofe in South Africa for the TEM and EDX characterizations. The authors also acknowledge Covenant University for funding this publication.

\section{References}

[1] S. Ahmed, M. Ahmad, B. L. Swami, and S. Ikram, "A review on plants extract mediated synthesis of silver nanoparticles for antimicrobial applications: a green expertise," Journal of Advanced Research, vol. 7, no. 1, pp. 17-28, 2016.
[2] I. Brigger, C. Dubernet, and P. Couvreur, "Nanoparticles in cancer therapy and diagnosis," Advanced Drug Delivery Reviews, vol. 54, no. 5, pp. 631-651, 2002.

[3] A. K. Gupta and M. Gupta, "Cytotoxicity suppression and cellular uptake enhancement of surface modified magnetic nanoparticles," Biomaterials, vol. 26, no. 13, pp. 1565-1573, 2005.

[4] R. Hao, R. J. Xing, Z. C. Xu, Y. L. Hou, S. Goo, and S. H. Sun, "Synthesis, functionalization, and biomedical applications of multifunctional magnetic nanoparticles," Advanced Materials, vol. 22 , no. 25 , pp. 2729-2742, 2010.

[5] M. Imran Din and A. Rani, "Recent advances in the synthesis and stabilization of nickel and nickel oxide nanoparticles: A green adeptness," International Journal of Analytical Chemistry, vol. 2016, Article ID 3512145, 14 pages, 2016. 
[6] H. Chen, J. Wang, D. Huang et al., "Plant-mediated synthesis of size-controllable Ni nanoparticles with alfalfa extract," Materials Letters, vol. 122, pp. 166-169, 2014.

[7] A. A. Mariam, M. Kashif, J. S. Arokiyara et al., "Bio-synthesis of Nio and Ni nanoparticles and their characterization," Digest Journal of Nanomaterials and Biostructures, vol. 9, no. 3, pp. 1007-1019, 2014.

[8] P. K. Jain, X. Huang, I. H. El-Sayed, and M. A. El-Sayed, "Noble metals on the nanoscale: Optical and photothermal properties and some applications in imaging, sensing, biology, and medicine," Accounts of Chemical Research, vol. 41, no. 12, pp. 1578-1586, 2008.

[9] M. Vaseem, N. Tripathy, G. Khang, and Y.-B. Hahn, "Green chemistry of glucose-capped ferromagnetic hcp-nickel nanoparticles and their reduced toxicity," RSC Advances, vol. 3, no. 25, pp. 9698-9704, 2013.

[10] I. P. Darsini, S. Shamshad, and M. John Paul, "Canna Indica (L.): A plant with potential healing powers: A review," International Journal of Pharma and Bio Sciences, vol. 6, no. 2, pp. 1-8, 2015.

[11] E. Abdullah, R. A. Raus, and P. Jamal, "Extraction and evaluation of antibacterial activity from selected flowering plants," American Medical Journal, vol. 3, no. 1, pp. 27-32, 2012.

[12] W. Woradulayapinij, N. Soonthornchareonnon, and C. Wiwat, "In vitro HIV type 1 reverse transcriptase inhibitory activities of Thai medicinal plants and Canna indicaL. rhizomes," Journal of Ethnopharmacology, vol. 101, no. 1-3, pp. 84-89, 2005.

[13] P. Rauwel, S. Küünal, S. Ferdov, and E. Rauwel, "A review on the green synthesis of silver nanoparticles and their morphologies studied via TEM," Advances in Materials Science and Engineering, vol. 2015, Article ID 682749, 9 pages, 2015.

[14] A. P. Kulkarni, A. A. Srivastava, P. M. Harpale, and R. S. Zunjarrao, "Plant Mediated Synthesis of Silver Nanoparticles - Tapping The Unexploited Sources," The Journal of Natural Product and Plant Resources, vol. 1, no. 4, pp. 100-107, 2011.

[15] S. C. Boca and S. Astilean, "Detoxification of gold nanorods by conjugation with thiolated poly(ethylene glycol) and their assessment as SERS-active carriers of Raman tags," Nanotechnology, vol. 21, no. 23, Article ID 235601, 2010.

[16] M. Rai, A. Yadav, and A. Gade, "CRC 675-current trends in phytosynthesis of metal nanoparticles," Critical Reviews in Biotechnology, vol. 28, no. 4, pp. 277-284, 2008.

[17] J. A. Adekoya, E. O. Dare, M. A. Mesubi, and N. Revaprasadu, "Synthesis and characterization of optically active fractal seed mediated silver nickel bimetallic nanoparticles," Journal of Materials, vol. 2014, pp. 1-9, 2014.

[18] S. Prabhu and E. K. Poulose, "Silver nanoparticles: mechanism of antimicrobial action, synthesis, medical applications, and toxicity effects," International Nano Letters, vol. 2, no. 32, pp. 110, 2012.

[19] N. Krishnamurthy, P. Vallinayagam, and D. Madhavan, Engineering Chemistry, PHI Learning Pvt. Ltd., 2014.

[20] A. A. Akinsiku, E. O. Dare, K. O. Ajanaku, J. A. Adekoya, S. O. Alayande, and A. O. Adeyemi, "Synthesis of silver nanoparticles by plant-mediated green method: optical and biological properties," Journal of Bionanoscience, vol. 10, no. 3, pp. 171-180, 2016.

[21] N. Ahmad and S. Sharma, "Green synthesis of silver nanoparticles using extracts of Ananas comosus," Green and Sustainable Chemistry, vol. 2, no. 4, pp. 141-147, 2012.

[22] A. A. Akinsiku, K. O. Ajanaku, J. A. Adekoya, and E. O. Dare, "Green synthesis, characterization of silver nanoparticles using Canna indica and Senna occidentalis leaf extracts," in
Proceedings of 2 nd Covenant University International Conference on African Development Issues, pp. 154-157, 2015.

[23] British Society for Antimicrobial Chemotherapy (BSAC, 1990).

[24] National Committee for Clinical Laboratory Standards (NCCLS), (1993).

[25] P. Aida, V. Rosa, F. Blamea, A. Thomas, and C. Salvador, "Paraguyan plants used in raditional medicine," Journal of Ethnopharmacology, vol. 16, pp. 93-98, 2001.

[26] Clinical and Laboratory Standards Institute (CLSI), 2006.

[27] J. H. Doughari, M. S. Pukuma, and N. De, "Antibacterial effects of Balanites aegyptiaca L. Drel. and Moringa oleifera Lam. on Salmonella typhi," African Journal of Biotechnology, vol. 6, no. 19, pp. 2212-2215, 2007.

[28] U. Guler, V. M. Shalaev, and A. Boltasseva, "Nanoparticle plasmonics: going practical with transition metal nitrides," Materials Today, vol. 18, no. 4, pp. 227-237, 2015.

[29] K. Sridharan, T. Endo, S.-G. Cho, J. Kim, T. J. Park, and R. Philip, "Single step synthesis and optical limiting properties of Ni-Ag and Fe-Ag bimetallic nanoparticles," Optical Materials, vol. 35, no. 5, pp. 860-867, 2013.

[30] S. Ponarulselvam, C. Panneerselvam, K. Murugan, N. Aarthi, K. Kalimuthu, and S. Thangamani, "Synthesis of silver nanoparticles using leaves of Catharanthus roseus Linn. G. Don and their antiplasmodial activities," Asian Pacific Journal of Tropical Biomedicine, vol. 2, no. 7, pp. 574-580, 2012.

[31] A. M. Smith, H. Duan, M. N. Rhyner, G. Ruan, and S. Nie, "A systematic examination of surface coatings on the optical and chemical properties of semiconductor quantum dots," Physical Chemistry Chemical Physics, vol. 8, no. 33, pp. 3895-3903, 2006.

[32] O. Kvítek, J. Siegel, V. Hnatowicz, and V. Švorčík, "Noble metal nanostructures influence of structure and environment on their optical properties," Journal of Nanomaterials, vol. 2013, Article ID 743684, p. 8, 2013.

[33] K. Raja, A. Saravanakumar, and R. Vijayakumar, "Efficient synthesis of silver nanoparticles from Prosopis juliflora leaf extract and its antimicrobial activity using sewage," Spectrochimica Acta Part A: Molecular and Biomolecular Spectroscopy, vol. 97, pp. 490-494, 2012.

[34] O. V. Kharissova, H. V. R. Dias, B. I. Kharisov, B. O. Pérez, and V. M. J. Pérez, “The greener synthesis of nanoparticles," Trends in Biotechnology, vol. 31, no. 4, pp. 240-248, 2013.

[35] N. Mntungwa, V. S. R. Pullabhotla, and N. Revaprasadu, "Facile synthesis of organically capped CdTe nanoparticles," Journal of Nanoscience and Nanotechnology, vol. 12, no. 3, pp. 2640-2644, 2012.

[36] I. M. Lifshic and V. V. Slezov, "The kinetics of precipitation from supersaturated solid solutions," Journal of Physics and Chemistry of Solids, vol. 19, no. 1-2, pp. 35-50, 1961.

[37] R. G. Haverkamp and A. T. Marshall, "The mechanism of metal nanoparticle formation in plants: limits on accumulation," Journal of Nanoparticle Research, vol. 11, no. 6, pp. 1453-1463, 2009.

[38] C. R. Andrighetti-Fröhner, K. N. de Oliveira, D. Gaspar-Silva et al., "Synthesis, biological evaluation and SAR of sulfonamide 4-methoxychalcone derivatives with potential antileishmanial activity," European Journal of Medicinal Chemistry, vol. 44, no. 2, pp. 755-763, 2009.

[39] F. Nazzaro, F. Fratianni, L. De Martino, R. Coppola, and V. De Feo, "Effect of essential oils on pathogenic bacteria," Pharmaceuticals, vol. 6, no. 12, pp. 1451-1474, 2013. 
[40] M. Marini, S. De Niederhausern, R. Iseppi et al., "Antibacterial activity of plastics coated with silver-doped organic-inorganic hybrid coatings prepared by sol-gel processes," Biomacromolecules, vol. 8, no. 4, pp. 1246-1254, 2007.

[41] J. Tan, W. Keller, S. Sohrabi, J. Yang, and Y. Liu, "Characterization of nanoparticle dispersion in red blood cell suspension by the lattice boltzmann-immersed boundary method," Nanomaterials, vol. 6, no. 2, article no. 30, 2016.

[42] C. Kleinstreuer and Z. Xu, "Mathematical modeling and computer simulations of nanofluid flow with applications to cooling and lubrication," Fluids, vol. 1, no. 2, p. 16, 2016.

[43] F. Benakashani, A. R. Allafchian, and S. A. H. Jalali, "Biosynthesis of silver nanoparticles using Capparis spinosa L. leaf extract and their antibacterial activity," Karbala International Journal of Modern Science, vol. 2, no. 4, pp. 251-258, 2016. 


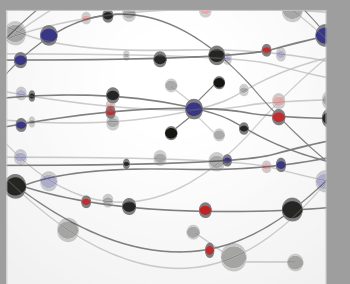

The Scientific World Journal
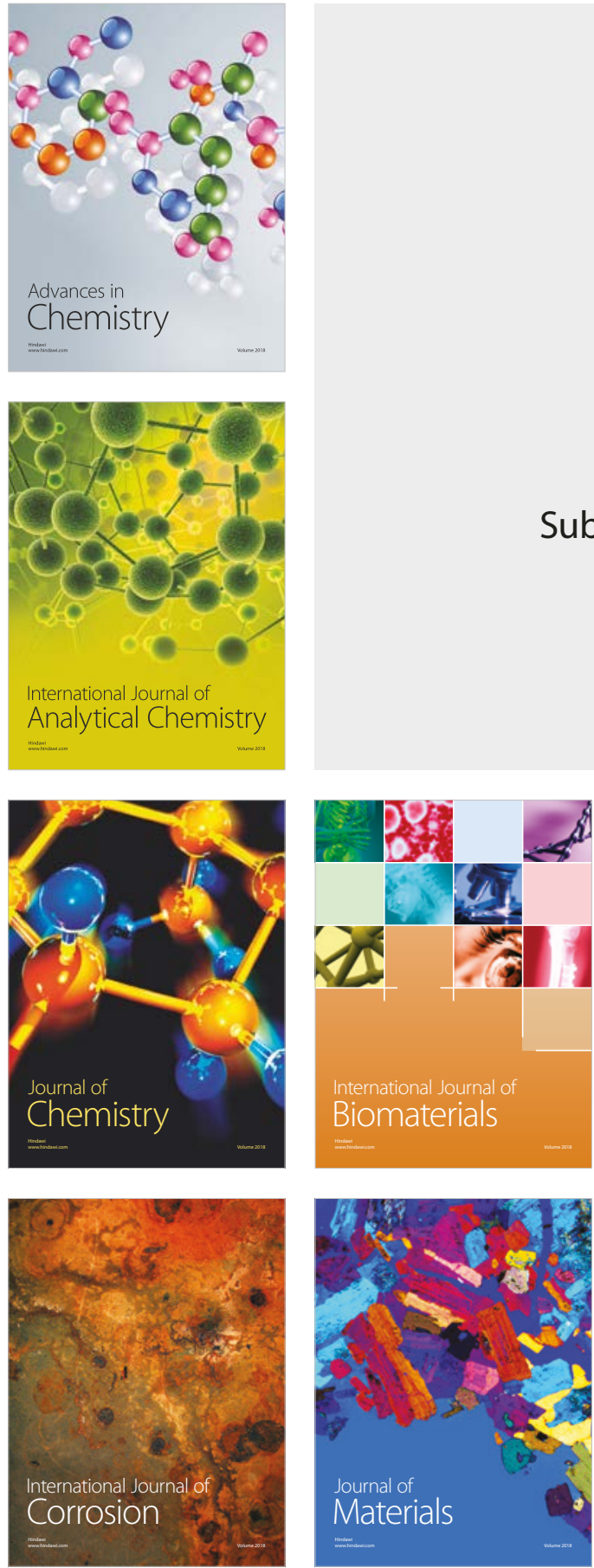

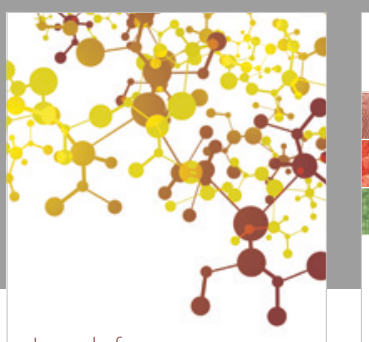

Journal of

Applied Chemistry
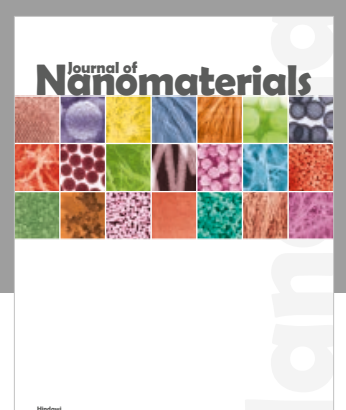

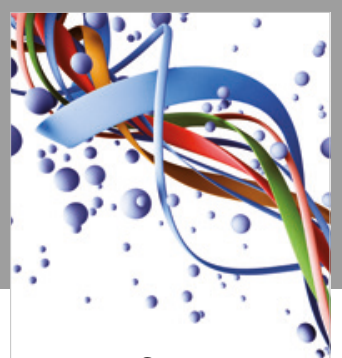

Scientifica

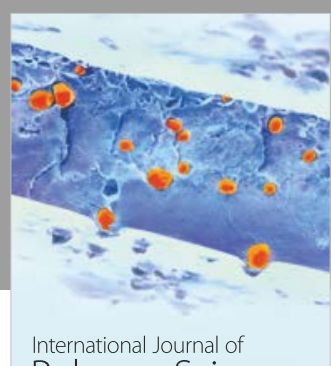

Polymer Science

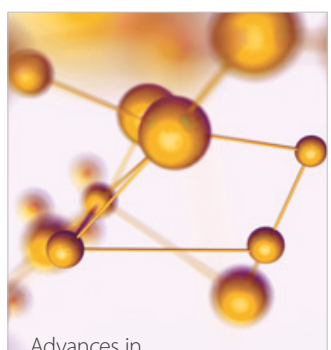

Physical Chemistry
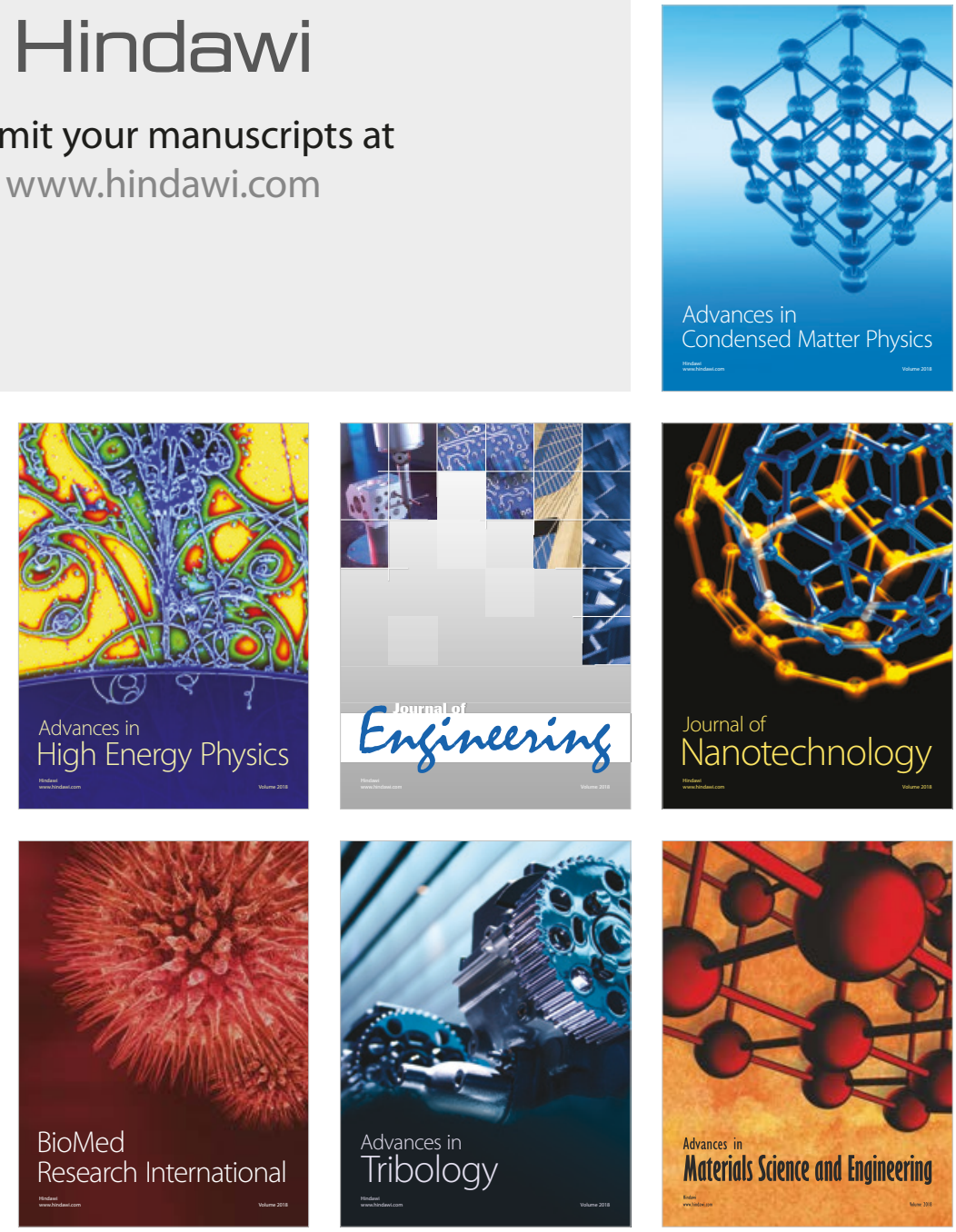